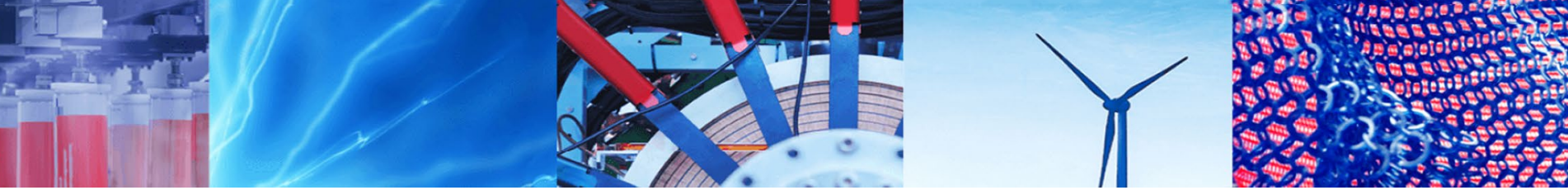

Research Article

\title{
Speciation of arsenic: a case study of PM1 in Zabrze
}

\author{
Katarzyna Nocoń ${ }^{1}$ [D $\cdot$ Wioletta Rogula-Kozłowska ${ }^{1}$
}

(c) The Author(s) 2019 OPEN

\begin{abstract}
The aim of the study was to determine ambient concentrations of soluble, inorganic form of $\operatorname{As}((\operatorname{As}(I I I)$ and $A s(V))$ in submicron atmospheric particles (PM1) in one of the most polluted region of Europe (Upper Silesia, Poland). Quantitative analyses of soluble As, soluble As (III) and As (V) after chromatographic separation and total As in digested PM1 samples were performed on the Elan 6100 DRC-e ICP-MS spectrometer. Results of analysis of the 15 randomly selected daily samples of PM1 from summer to winter season were presented. We showed that $\mathrm{As}(\mathrm{V})$ is dominating soluble, inorganic form of As in ambient air of selected city in Upper Silesia (Zabrze). Ambient concentrations of As(III) and As(V) as well as their mass percentages in water-soluble and total As changed seasonally. In winter season, when emissions from coal combustion prevailed, ambient concentration of soluble $\mathrm{As}(\mathrm{V})$ was about three times higher than in summer and accounted for $55 \%$ of total As. Ambient mass of As(III) was about 3.7\% of the total As mass. During summer, when the sources of As may be more differentiated (industry, traffic, secondary emission from some surfaces, e.g., soils, roads, farmlands and dumps), soluble As(V) accounted for $23 \%$ of total As while soluble As(III) $6.7 \%$.
\end{abstract}

Keywords Arsenic (V) · Arsenic (III) · Water-soluble arsenic · PM1

\section{Introduction}

Arsenic (As), belonging to toxic elements, is a metalloid widely spread in environment. As in the air originates both from natural and anthropogenic sources. Anthropogenic emissions (metal smelting, burning of some fuels, e.g., gas and carbon coal) are responsible for approximately two-thirds of the total As emissions to the atmosphere; their natural sources are: volcanoes, forest fires and sea spray [1]. It was reported that As concentration in urban and industrial atmosphere was significantly higher than in rural areas. The typical concentration of As in Europe ranges $0.2-1.5 \mathrm{ng} / \mathrm{m}^{-3}$ in rural areas and $0.5-3 \mathrm{ng} / \mathrm{m}^{-3}$ in urban areas, and usually is below $50 \mathrm{ng} / \mathrm{m}^{-3}$ in industrial areas [2]. It is known that particulate matter (PM) generated by anthropogenic sources consists mostly of fine particles, with the domination of particles below $1 \mu \mathrm{m}, \mathrm{PM} 1[3,4]$. The fine PM particles, due to it well-developed surface area, has ability to cumulate metals and metalloids [5]. For instance, studies on fractionated PM have shown that in the Polish urban areas, PM1-bound metal mass is approximately 70-90\% of total PM-bound metal mass [6-8]. Moreover, PM1, due to its physical properties, is characterized by long residence time in the atmosphere and the tendency to migrate over long-distances. Depending on metrological conditions, PM1-bound toxic elements can be spread to distant places from the one in which they were emitted, end remains airborne for days or even weeks, as washout processes are least efficient for cleansing particles in these size bins $[9,10]$. In a densely populated industrial area, during period when residential heating is active, increase in fine PM and fine PM-bound As were observed. This factor affects the state of air quality, unfavorable from the point of view of human health, because fine PM including PM1 can be deeply inhaled into the

Katarzyna Nocoń, katarzyna.nocon@ipis.zabrze.pl | 'Institute of Environmental Engineering Polish Academy of Sciences, 34 M. Skłodowskiej-Curie St., 41-819 Zabrze, Poland.

SN Applied Sciences (2019) 1:450 | https://doi.org/10.1007/s42452-019-0456-x

Received: 8 February 2019 / Accepted: 4 April 2019 / Published online: 12 April 2019 
unciliated airways of the lung (the alveolar region) and absorbed directly into the pulmonary circulation system [11]. However, As toxicity and mobility are significantly correlated with its speciation and oxidation state in the environment. In general, inorganic As species are more toxic than organic As species. As(III) is both more toxic and more mobile in the environment compared to $\mathrm{As}(\mathrm{V})$ [12]. Depending on the environmental conditions (especially $\mathrm{pH}$ and oxydo-reduction conditions) as well as on chemical nature of particular groups of As compounds, different forms of arsenic may be interconverted. Ambient air is a specific part of environment, which is under dynamic physical and chemical transformation affected mainly by meteorological conditions (such as humidity, temperature and insolation). Possible oxidation of As(III) to $\mathrm{As}(\mathrm{V})$ by atmospheric oxygen has to be considered, especially at high $\mathrm{pH}$ [13]. Probably, atmospheric ozone could play a similar role as oxygen. Although its concentration in the air is less than oxygen and changeable, it has stronger oxidizing properties. Most of As in the atmosphere can be found in the particulate phase; $<10 \%$ is present in the vapor phase. Anthropogenic emissions, e.g., from smelting or fossil fuel combustion, introduce considerably amounts of the volatile As to the atmosphere (mainly As oxides), which preferentially adsorbs or condenses on the fine particles. Therefore, PM can be significantly enriched in As compared to the continental crust [13]. The source of particulate As can also resuspend dust from roads and soils. Concentrations and chemical composition of PM and PM-bound species of As are very site-dependent. They are shaped by regional and local emission sources; As bound to fine PM can be transported also from distant areas. In the regions with significant industrial emission, concentrations of As (and their species) will be determined by it. In areas with diversified sources of emissions (suburban areas, city centers, etc.), concentrations of As (and their species) are shaped mainly by municipal emission or time-stable road traffic emissions [14]. X-ray analysis of PM from industrial area showed that $A$ s bound to PM occurs as: $\mathrm{Ca}_{3} \mathrm{Sr}_{2}\left(\mathrm{AsO}_{4}\right) 2.5(\mathrm{PO} 4) 0.5(\mathrm{OH}), \mathrm{As}_{2} \mathrm{O}_{3}$ and $\mathrm{As}_{2} \mathrm{O}_{5}$ [15]. Analysis of PM has revealed that inorganic arsenic species, in particular $\mathrm{As}(\mathrm{V})$, is the predominant species in atmospheric PM [2016]. Their ambient concentrations are higher in PM from industrial areas than in PM from semi-urban sites [14-17]. For example, high concentrations of PM2.5-bound As $\left(6.4 \mathrm{ng} / \mathrm{m}^{3}\right.$ for total As, $0.9 \mathrm{ng} / \mathrm{m} 3$ for As(III) and $5.5 \mathrm{ng} / \mathrm{m}^{3}$ for As(V)) were noted in area close to Spain cooper smelter [17]. Another research showed domination of As(III) in PM2.5-bound As and higher share of As(III) with increasing concentration of PM2.5-bound As [15]. Studies on As speciation in size-resolved PM shown that more toxic As(III) tends to concentrate in the fine fraction of PM (PM1 or PM2.5), and the shares of $\mathrm{As}(\mathrm{III})$ in total PM-bound As increased with decreasing PM diameter [14-16].

Summarizing the above, the speciation of As in fine PM is of great significance because it may provide information about their species amounts available for living organisms, thus potentially harmful, e.g., after inhaled exposure and also that more stable in environment, thus less danger for ecosystem.

Although urban PM belongs to the most frequently investigated environmental matrices, the As speciation in fine PM samples is still rather scarce, especially speciation of their water-soluble compounds in PM1.

The aim of the study was to conduct speciation of soluble form of inorganic As (As(III) and $A s(V)$ ) in PM1 samples from one of the most polluted region of Europe (Zabrze in Upper Silesia, Poland). Upper Silesia is the most industrialized and urbanized region of Poland. Important industries in Upper Silesia include coal mining, iron and steel production, power plants, cokeries, waste incinerators and chemicals production. In the last 30 years, in this region, emissions have been significantly reduced; however, PM concentrations are there still one of the highest in the EU, mainly because of dense and obsolete housing, where poor-quality hard coal, scrap and household garbage are burnt in inefficient ovens to warm flats $[18,19]$. Since late autumn (the beginning of heating season), the fossil fuel and biomass combustion grows significantly and lasts all heating period. Such annual emission state is reflected in seasonal changes in concentrations of PM and of the PM-related elements including As [6-8]. For this reason, authors decided to check if and how the growing emission from fuels combustion in winter affects results of the speciation of water-soluble PM1-bound inorganic As.

\section{Materials and methods}

\subsection{Sampling area and the collection of PM1 samples}

PM1 samples were collected at an urban background station in central Zabrze (50_1805800N, 18_4601800E). The neighborhood of the sampling site consisted of a trunk road (approx. $500 \mathrm{~m}$ to the north), blocks of flats and residential houses (to the east), Zabrze city center with residential and commercial housing (to the south and southeast) and blocks of flats and allotments (to the west). The surrounding houses were either connected to the district heating network or heated with local coal-, gas- or electricity-powered boilers [7].

PM1 was collected onto Quartz air-sampling filters (Whatman, Ø $4.7 \mathrm{~cm}$; QM-A) using a low-volume $\left(2.3 \mathrm{~m}^{3} / \mathrm{h}\right.$ ) 
air sampler, (Twin Dust; Zambelli Milan, Italy) equipped with the PM1 sampling head (TSI; MN, USA). The 24-h PM1 samples were collected in summer from 24 June to 24 August 2014 and in winter from January 8 to March 8 , 2015. In the paper, analysis results for 15 samples for each season are presented. Samples of PM1 for the study were randomly selected.

PM1 samples were conditioned and weighed in a weighing room at the air temperature of $20 \pm 1{ }^{\circ} \mathrm{C}$ and air relative humidity of $50 \pm 5 \%$ by means of an MYA 5.3YF microbalance (1 mg resolution, RADWAG, Radom, Poland). A methodology of gravimetric analysis is described in detail in [20]. After weighting, the filters with PM were cut into four equal pieces with ceramic knife. One part, which used for PM-bound As speciation and determination of soluble As, was placed in the refrigerator at $-20^{\circ} \mathrm{C}$ under conditions of As species preservation. The next was used in determination of total As. The other two were used in another study [20, 21].

\subsection{Chemical analysis}

\subsubsection{Chemicals and reagents}

To perform total As analysis, the following suprapure acids (Merck, Darmstadt, Germany) were used: nitric acid (65\%), hydrofluoric acid (40\%) and perchloric acid (70\%).

To perform As speciation analysis, the following substances were used: ultrapure ammonium nitrate (Merck, Darmstadt, Germany), ammonium solution 25\%, suprapure (Merck), sodium arsenate dibasic heptahydrate (Sigma-Aldrich, St Louis, MO, USA) and sodium arsenite (Sigma-Aldrich).

Stock solutions of As compounds containing $1000 \mathrm{mg} / \mathrm{l}$ As were prepared in water and maintained at $4{ }^{\circ} \mathrm{C}$ (in a fridge). Appropriate dilutions by weight of the stock solutions with distilled water were prepared daily to obtain the required concentration. Mobile phase was prepared from ultrapure ammonium nitrate (Merck, Darmstadt, Germany), and the $\mathrm{pH}$ was adjusted by the addition of ammonium solution ( $25 \%$, suprapure (Merck). This solution was filtered through a $0.45-\mu \mathrm{m}$ membrane filter before use.

All solutions and standards were prepared with the Milli-Q-Gradient ultrapure deionized water (Millipore, Merck Darmstadt, Germany), whose electrolytic conductivity was $<0.05 \mu \mathrm{S} / \mathrm{cm}$.

\subsubsection{Extraction procedure}

\section{Total content (acid extraction/digestion)}

PM1 samples collected on filters and blank filters were placed in PTFE vessels and flooded with $5 \mathrm{~mL}$ of nitric acid,
$1 \mathrm{~mL}$ of hydrofluoric acid and $1 \mathrm{~mL}$ of perchloric acid and subjected to microwave mineralization (Multiwave 3000 microwave digestion system, Anton-Paar, France). Mineralization furnace parameters were: a pressure rise of $0.3 \mathrm{bar} / \mathrm{s} ; 240^{\circ} \mathrm{C}$; pressure $60 \mathrm{bar}$ and mineralization time $50 \mathrm{~min}$. The digested samples along with several washings were transferred to polypropylene flask with a volume $25 \mathrm{ml}$.

The arsenic content in the empty filter was $0.11 \mathrm{ppb}$. This value was subtracted from the arsenic content determined for each of the PM1 samples on filter.

\section{Water-soluble fraction (water extraction)}

PM1 samples collected on filters and blank filters were extracted with $25 \mathrm{~mL}$ of deionized water $(\mathrm{pH} \sim 5.6)$ first in ultrasonic bath $\left(15^{\circ} \mathrm{C}\right)$ for $40 \mathrm{~min}$ and then were shaken overnight $\left(60 \mathrm{rpm}, 18^{\circ} \mathrm{C}\right)$. Water extracts of PM and of blanks were filtered through a $0.22-\mu \mathrm{m}$ PSE membrane filter and analyzed as described below. Arsenic content in empty filter water extract was below limit of detection.

\subsubsection{Apparatus}

Chromatographic separation of As was performed on high-performance liquid chromatography (HPLC) system (series 200 LC, PerkinElmer). The system consisted of Series 200 LC gradient pump, Series 200 LC autosampler and Series 200 LC Peltier Column Oven.

Quantitative analyses of soluble As, its species after chromatographic separation and total As in digested PM1 samples were performed on the Inductively Coupled Plasma Mass Spectrometer (ICP-MS) Elan 6100 DRC-e (Perkin Elmer, Waltham, MA, USA).

Chromatographic and ICP-MS operating parameters are presented in Table 1.

\subsubsection{Quality control}

By definition, the limit of quantitation is the smallest concentration of the analyte determined in the sample, which can be quantitated with the assumed accuracy and precision [22]. For this purpose, a series of measurements $(n=6)$ for $\mathrm{As}(\mathrm{III})$ and $\mathrm{As}(\mathrm{V})$ calibration solution $(0.2 \mu \mathrm{g} / \mathrm{l})$, a lower concentration solution $(0.15 \mu \mathrm{g} / \mathrm{l})$ and solutions of higher concentrations $(0.25 \mu \mathrm{g} / \mathrm{l}$ and $0.30 \mu \mathrm{g} / \mathrm{l})$ were made. The measure of precision was the value of the relative standard deviation of repeatability (RSD \%) of the obtained results of As peak area. It was assumed that the precision of $8 \%$ will be sufficient. This assumption was met in the case of As(III) for a solution with a concentration of $0.2 \mu \mathrm{g} / \mathrm{l}$, and for $\mathrm{As}(\mathrm{V})$ for a solution with a concentration of $0.30 \mu \mathrm{g} / \mathrm{l}$. It was assumed that the limit of detection is 
Table 1 Operating conditions for HPLC and ICP-MS systems

\begin{tabular}{ll} 
HPLC parameters & \\
Column & Hamilton PRP-X100; $150 \mathrm{~mm} \times 4.6 \mathrm{~mm}, 5 \mu \mathrm{m}$ \\
Mobile phase & $\mathrm{A}: 20 \mathrm{mM} \mathrm{NH}_{4} \mathrm{NO}_{3} \mathrm{pH}=8.7$ \\
& $\mathrm{~B}: 60 \mathrm{mM} \mathrm{NH}_{4} \mathrm{NO}_{3} \mathrm{pH}=8.7$ \\
Flow rate during the analysis & $1.1 \mathrm{ml} / \mathrm{min}$ \\
Elution program & $0-2.0 \mathrm{~min} .100 \% \mathrm{~A}$ \\
& $2.0-3.0 \mathrm{~min}$ from $100 \%$ A to $100 \% \mathrm{~B}$ \\
& $3.0-6.5 \mathrm{~min} 100 \% \mathrm{~B}$ \\
Volume of sample & Rinsing $6.5-9.5 \mathrm{~min} 100 \% \mathrm{~A}$ \\
Column temperature & $100 \mu \mathrm{ll}$ \\
ICP-MS parameters & $30^{\circ} \mathrm{C}$ \\
Generator power RF & \\
Plasma gas flow & $1125 \mathrm{~W}$ \\
Nebulizer gas flow & $15 \mathrm{l} / \mathrm{min}$ \\
Auxiliary gas flow & $0.76-0.82 \mathrm{l} / \mathrm{min}$ \\
Nebulizer & $1.15 \mathrm{l} / \mathrm{min}$ \\
Torch & Cross \\
Cones & Quartz \\
Scan mode & Nickel \\
Dwell time & Peak hopping \\
Sweeps & $250 \mathrm{~ms}$ \\
\hline
\end{tabular}

Table 2 Validation parameters

\begin{tabular}{lll}
\hline Parameter & As(III) & As(V) \\
\hline Limit of detection $(\mu \mathrm{g} / \mathrm{l})$ & 0.07 & 0.1 \\
Limit of quantitation $(\mu \mathrm{g} / \mathrm{l})$ & 0.2 & 0.3 \\
Repeatability (as RSDs) $\%$ & 7.6 & 6.8 \\
Recovery \% & 91 & 104
\end{tabular}

equal to one-third of the limit of quantitation. The recovery efficiency was measured by spiking quartz filter and $2 \mathrm{mg}$ of Reference Material (CRM 1648a urban particulate matter; obtained from the National Institute of Standard and Technology (NIST)), put on it previously, with a As(III) and $\mathrm{As}(\mathrm{V})$ standard solution $(0.5 \mu \mathrm{g} / \mathrm{l})$ and subjecting them to the same extraction and analysis methods that used collected PM1 samples.

Parameters mentioned above are presented in Table 2.

The accuracy of the method for the total As content was calculated as As recovery from the mineralized CRM 1648a PM sample (according to the methodology described in 2.2.2). Arsenic recovery was $80 \%$.

\subsubsection{Statistical analysis}

The obtained results were analyzed using the Statistica for Windows package, version 8.0 (StatSoft, Poland). Summary statistics (mean, standard deviation, minimum and maximum) were determined for each PM1, PM1-bound total As, PM1-bound water-soluble As, PM1-bound watersoluble $\mathrm{As}(\mathrm{V})$ and $\mathrm{As}(\mathrm{III}), \mathrm{As}(\mathrm{V}) / \mathrm{As}(\mathrm{III})$ ratio, percentage of water-soluble PM1-bound As(III) and As(V) in PM1-bound total As. Since the concentrations of the measured analytes were not normally distributed, a nonparametric Mann-Whitney $U$ test was used to compare winter-summer differences in the concentrations (aassump. $=0.05$ ).

\section{Result and discussion}

In winter season the mean concentration of PM1 was $38.12 \mu \mathrm{g} / \mathrm{m}^{3}$; that was 3.5 times higher than in summer season (differences were statistically significant; $p<0.05$; Table 3). In winter, mean concentration of total and soluble As were 3.26 and $1.86 \mathrm{ng} / \mathrm{m}^{3}$, respectively; they were 1.2 and 3 times higher than in summer (Table 3 ). In earlier research of PM1 from Zabrze, similar seasonal changes of concentrations of PM1 and PM1-bound total As were found $[6,8]$.

Results of water-soluble PM1-bound As speciation are presented in Table 4. They show higher daily ambient concentration of PM1-bound As(V) than As(III) in Zabrze in both measuring periods (winter/summer). An example of chromatogram of As species in PM1 water extract from summer and winter season is presented in Fig. 1. The mean ambient concentrations in summer season were $0.15 \mathrm{ng} / \mathrm{m}^{3}$ for $\mathrm{As}(\mathrm{III})$ and $0.54 \mathrm{ng} / \mathrm{m}^{3}$ for $\mathrm{As}(\mathrm{V})$ and 0.12 and 
Table 3 Ambient concentrations of PM1 $\left(\mu \mathrm{g} / \mathrm{m}^{3}\right)$, PM1-bound total and soluble As $\left(\mathrm{ng} / \mathrm{m}^{3}\right)$
Table 4 Ambient

concentration of water-soluble PM1-bound As(III) and As(V) $\left(\mathrm{ng} / \mathrm{m}^{3}\right)$ and their percentage in PM1-bound total As (\%)

\begin{tabular}{|c|c|c|c|c|c|c|c|}
\hline \multicolumn{4}{|l|}{ Summer season } & \multicolumn{4}{|l|}{ Winter season } \\
\hline Collection date & $\begin{array}{l}\mathrm{PM}^{*} \\
\mu \mathrm{g} / \mathrm{m}^{3}\end{array}$ & $\begin{array}{l}\text { As total* } \\
\mathrm{ng} / \mathrm{m}^{3}\end{array}$ & $\begin{array}{l}\text { As soluble* } \\
\mathrm{ng} / \mathrm{m}^{3}\end{array}$ & Collection date & $\begin{array}{l}\mathrm{PM}^{*} \\
\mu \mathrm{g} / \mathrm{m}^{3}\end{array}$ & $\begin{array}{l}\text { As total* } \\
\mathrm{ng} / \mathrm{m}^{3}\end{array}$ & $\begin{array}{l}\text { As soluble* } \\
\mathrm{ng} / \mathrm{m}^{3}\end{array}$ \\
\hline $24-06-2014$ & 10.30 & 2.74 & 0.57 & 09-01-2015 & 24.20 & 3.02 & 1.84 \\
\hline $28-06-2014$ & 12.46 & 3.59 & 0.34 & $13-01-2015$ & 14.82 & 2.96 & 0.81 \\
\hline 02-07-2014 & 9.23 & 3.78 & 0.69 & $17-01-2015$ & 38.98 & 5.35 & 0.87 \\
\hline 06-07-2014 & 16.78 & 5.05 & 1.29 & 21-01-2015 & 29.66 & 3.30 & 2.14 \\
\hline 11-07-2014 & 8.15 & 2.22 & 0.45 & 24-01-2015 & 17.68 & 1.62 & 1.30 \\
\hline $16-07-2014$ & 11.40 & 4.90 & 1.38 & 29-01-2015 & 34.83 & 2.67 & 2.02 \\
\hline 21-07-2014 & 18.92 & 2.14 & 0.63 & 03-02-2015 & 67.84 & 3.56 & 1.86 \\
\hline $25-07-2014$ & 9.22 & 1.47 & 0.28 & 06-02-2015 & 32.49 & 1.76 & 1.38 \\
\hline 28-07-2014 & 12.56 & 1.68 & 0.83 & $14-02-2015$ & 93.48 & 7.37 & 5.24 \\
\hline 02-08-2014 & 13.21 & 1.08 & 0.62 & $19-02-2015$ & 56.91 & 3.38 & 2.28 \\
\hline 07-08-2014 & 6.47 & 1.45 & 0.44 & $23-02-2015$ & 38.62 & 3.49 & 2.14 \\
\hline $11-08-2014$ & 6.49 & 1.53 & 0.39 & $26-02-2015$ & 34.37 & 3.02 & 1.27 \\
\hline $16-08-2014$ & 10.41 & 1.46 & 0.47 & 02-03-2015 & 18.76 & 1.80 & 1.00 \\
\hline 20-08-2014 & 4.58 & 4.22 & 0.42 & 05-03-2015 & 20.06 & 2.40 & 1.06 \\
\hline 24-08-2014 & 7.68 & 2.32 & 0.87 & 07-03-2015 & 49.12 & 3.27 & 2.65 \\
\hline Minimum & 4.58 & 1.08 & 0.28 & Minimum & 14.82 & 1.62 & 0.81 \\
\hline Maximum & 18.92 & 5.05 & 1.38 & Maximum & 93.48 & 7.37 & 5.24 \\
\hline Mean & 10.52 & 2.64 & 0.64 & Mean & 38.12 & 3.26 & 1.86 \\
\hline SD & 3.88 & 1.34 & 0.33 & SD & 21.39 & 1.46 & 1.09 \\
\hline
\end{tabular}

*Element whose summer and winter concentrations in Zabrze are statistically significantly different (according to the Mann-Whitney $U$ test; aassump. $=0.05$, pcomp. $<0.05$ )

\begin{tabular}{|c|c|c|c|c|c|c|c|c|c|}
\hline \multicolumn{5}{|l|}{ Summer season } & \multicolumn{5}{|l|}{ Winter season } \\
\hline Collection date & $\operatorname{As}(I I I)$ & $\operatorname{As}(\mathrm{V})^{*}$ & $\mathrm{As}(\mathrm{III})$ & $\mathrm{As}(\mathrm{V})$ & Collection date & $\mathrm{As}(\mathrm{III})$ & $\mathrm{As}(\mathrm{V})^{*}$ & $\mathrm{As}(\mathrm{III})$ & $\mathrm{As}(\mathrm{V})$ \\
\hline & $\mathrm{ng} / \mathrm{m}^{3}$ & $\mathrm{ng} / \mathrm{m}^{3}$ & $\%$ & $\%$ & & $\mathrm{ng} / \mathrm{m}^{3}$ & $\mathrm{ng} / \mathrm{m}^{3}$ & $\%$ & $\%$ \\
\hline $24-06-2014$ & 0.05 & 0.51 & 1.99 & 18.56 & 09-01-2015 & 0.09 & 1.74 & 2.88 & 57.57 \\
\hline $28-06-2014$ & 0.07 & 0.29 & 1.82 & 8.18 & $13-01-2015$ & 0.19 & 0.60 & 6.54 & 20.43 \\
\hline $02-07-2014$ & 0.12 & 0.59 & 3.30 & 15.68 & $17-01-2015$ & 0.34 & 0.49 & 6.41 & 9.16 \\
\hline 06-07-2014 & 0.23 & 1.16 & 4.60 & 23.02 & 21-01-2015 & 0.17 & 1.94 & 5.05 & 58.87 \\
\hline $11-07-2014$ & 0.10 & 0.32 & 4.38 & 14.59 & 24-01-2015 & 0.07 & 1.21 & 4.15 & 74.66 \\
\hline $16-07-2014$ & 0.30 & 1.04 & 6.02 & 21.08 & 29-01-2015 & 0.07 & 1.91 & 2.60 & 71.63 \\
\hline 21-07-2014 & 0.26 & 0.74 & 12.15 & 34.71 & $03-02-2015$ & 0.11 & 1.75 & 3.08 & 49.22 \\
\hline $25-07-2014$ & 0.11 & 0.14 & 7.28 & 9.70 & 06-02-2015 & 0.06 & 1.33 & 3.43 & 75.51 \\
\hline $28-07-2014$ & 0.24 & 0.61 & 14.55 & 36.38 & $14-02-2015$ & 0.25 & 5.26 & 3.40 & 71.43 \\
\hline $02-08-2014$ & 0.15 & 0.48 & 13.95 & 44.65 & 19-02-2015 & 0.05 & 2.26 & 1.57 & 66.78 \\
\hline 07-08-2014 & 0.10 & 0.38 & 6.97 & 26.15 & 23-02-2015 & 0.09 & 2.08 & 2.45 & 59.61 \\
\hline $11-08-2014$ & 0.14 & 0.30 & 8.94 & 19.86 & $26-02-2015$ & 0.06 & 1.22 & 2.08 & 40.36 \\
\hline $16-08-2014$ & 0.12 & 0.37 & 8.48 & 25.44 & 02-03-2015 & 0.06 & 1.01 & 3.22 & 56.40 \\
\hline $20-08-2014$ & 0.11 & 0.37 & 2.61 & 8.70 & 05-03-2015 & 0.07 & 0.99 & 2.78 & 41.33 \\
\hline $24-08-2014$ & 0.09 & 0.79 & 3.95 & 34.20 & 07-03-2015 & 0.11 & 2.61 & 3.29 & 79.87 \\
\hline Minimum & 0.05 & 0.14 & 1.82 & 8.18 & Minimum & 0.05 & 0.49 & 1.57 & 9.16 \\
\hline Maximum & 0.30 & 1.16 & 14.55 & 44.65 & Maximum & 0.34 & 5.26 & 6.54 & 79.87 \\
\hline Mean & 0.15 & 0.54 & 6.73 & 22.73 & Mean & 0.12 & 1.76 & 3.53 & 55.52 \\
\hline SD & 0.08 & 0.29 & 4.18 & 10.97 & SD & 0.08 & 1.14 & 1.45 & 20.50 \\
\hline
\end{tabular}

*Element whose summer and winter concentrations in Zabrze are statistically significantly different (according to the Mann-Whitney $U$ test; aassump. $=0.05$, pcomp. $<0.05$ ) 
Fig. 1 Chromatogram of As(III) and As (V) in PM1 water extract (summer-black and winterblue)

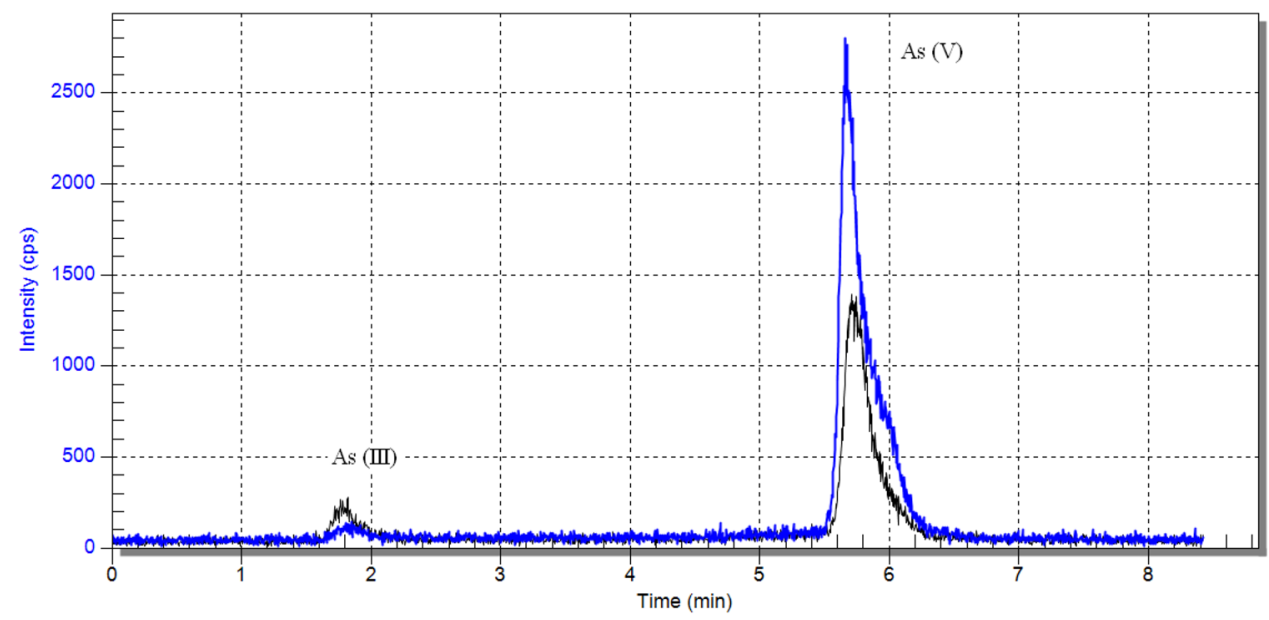

$1.76 \mathrm{ng} / \mathrm{m}^{3}$ for As (III) and As(V), respectively, in winter season. So, in the winter season, the mean concentration of $\mathrm{As}(\mathrm{V})$ was on average about three times higher than in the summer season, while the mean concentration of As(III) was on average 1.4 times lower. The mass percentages of water-soluble $\mathrm{As}(\mathrm{III})$ and $\mathrm{As}(\mathrm{V})$ in the total As mass were about 3.5 and $55 \%$ in winter; in summer season, they were about 6.7 and 23\%, respectively. The total mass share of water-soluble inorganic As species ( $\mathrm{As}(\mathrm{III})+\mathrm{As}(\mathrm{V}))$ was two times higher in winter than in summer (Tables 3 and 4). Currently, there are no data available to compare to watersoluble PM1-bound As(III) and As(V) that were collected anywhere. It can be found in literature a study with different origins of samples, their grain size and characteristics of test sites. The case study, conducted in Czech Republic, presents results of water-soluble As species in two urban dust samples collected in Prague: one was collected in automobile tunnel Letna (particles between 3 and $4 \mu \mathrm{m}$; jet-milled and homogenized in blender before analysis) and second one sampled from filters of the air conditioner system in building close to the highway (particles $<63 \mu \mathrm{m}$; dried and sieved before analysis). As(III) represented $0.8 \%$ and $2.5 \%$ of the total As content in the water extract of tunnel dust and building dust, respectively (extraction time $=16 \mathrm{~h}) . \mathrm{As}(\mathrm{V})$ concentrations in analyzed samples were below detection limit [23].

On the basis of the ratio of oxidized and reduced watersoluble As specie, a greater predominance of $A s(V)$ over As(III) in winter than in summer can be seen (Table 4). Daily values of the $\mathrm{As}(\mathrm{V}) / \mathrm{As}(\mathrm{III})$ ratio did not exceed 10 in summer season (mean value was about 4); in winter, they were higher than 10 in 13 per 15 analyzed samples of PM1 (mean value was about 19). We tried to compare the seasonal differences of $\mathrm{As}(\mathrm{V}) / \mathrm{As}(\mathrm{III})$ ratio in $\mathrm{PM} 1$ from Zabrze and Katowice (city located about $15 \mathrm{~km}$ from Zabrze and roughly under the influence of similar PM emission sources). As species in PM1from Zabrze was extracted with water, and from Katowice, As(III) was extracted with citric acid/sodium citrate buffer and $\mathrm{As}(\mathrm{V})$ calculated as As total-As(III). Mean value of $\mathrm{As}(\mathrm{V}) / \mathrm{As}$ (III) ratio in PM1 in Katowice was higher in winter $(4.60=5.56 / 1.21)$ than in summer $(2.86=1.92 / 0.67)$ [14]. So, mean $\mathrm{As}(\mathrm{V}) / \mathrm{As}(\mathrm{III})$ ratio in $\mathrm{PM} 1$ both from Zabrze and Katowice was higher in winter than in summer, but in both seasons, the predominance of $\mathrm{As}(\mathrm{V})$ over $\mathrm{As}(\mathrm{III})$ in those PM1 was greater in Zabrze than in Katowice.

In environment, the common pentavalent compounds of inorganic arsenic are arsenic pentoxide, arsenic acid and arsenates (e.g., lead arsenate and calcium arsenate) and trivalents: arsenic trioxide, sodium arsenite and arsenic trichloride [2]. In ash from coal combustion, As is present mainly as halides, oxides, sulfides and hydride compounds [24]. X-ray analysis of PM collected in area near a metallurgical industrial plants showed that $A s$ was present in most as: $\mathrm{Ca}_{3} \mathrm{Sr}_{2}\left(\mathrm{AsO}_{4}\right) 2.5(\mathrm{PO} 4) 0.5(\mathrm{OH}), \mathrm{As}_{2} \mathrm{O}_{3}$ and $\mathrm{As}_{2} \mathrm{O}_{5}$ [15].

Solubility of PM-bound As species is dependent on which chemical compounds they are present. There are other factors than can influence the leaching behavior of As species. In the opinion of some authors, trace elements in soluble fraction are possibly adsorbed on particle surfaces and are easily released to aqueous solutions. [25]. So, based on this supposition, also the composition of the PM surface layer could be important factor influencing As leachability. Analysis of the chemical composition of a surface layer of PM1 in Zabrze showed that carbon is a dominating element (mean about $79 \%$ of all detected elements). Mean shares of the rest of analyzed chemical elements were: oxygen: $14-16 \%$, silicon and aluminum: $1.5-4 \%$, nitrogen and sulfur: $0.4-1.0 \%$, calcium and chloride: $0.12-0.31 \%$ [26].

Dominating carbon probably primarily play a role of sorbent, on which As compounds such as oxides are surface-absorbed, although As can be present as carbonatebound too. 


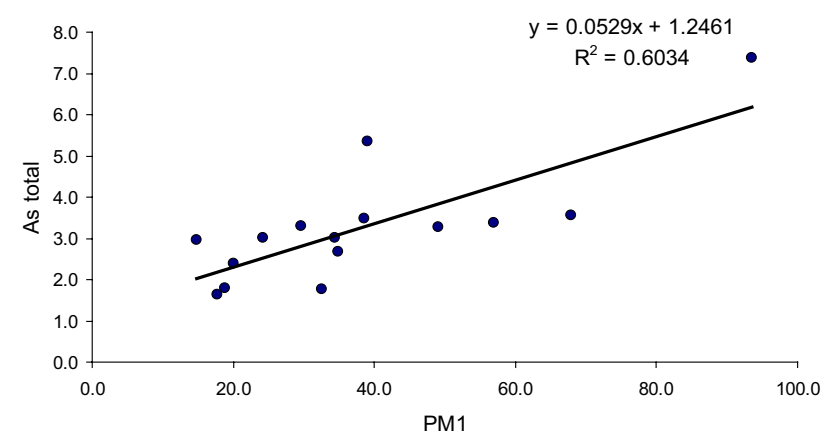

Fig. 2 As total versus PM1 in winter

The differences in seasonal concentrations of watersoluble As(III) and As(V) in PM1 in Zabrze could be also connected with different concentrations of soluble macrocomponents in PM1 in both seasons. In PM1 samples collected during measuring campaign (described in 2.1), also organic and elemental carbon (OC and EC), selected water-soluble ions were determined and presented in previous paper [20]. The study has shown that the means of the winter concentrations of PM1-bound $\mathrm{OC}, \mathrm{NO}_{3}{ }^{-}$and $\mathrm{Cl}$ were 5, 7 and 20 times higher than the summer ones, those of PM1-bound $\mathrm{EC}, \mathrm{F}^{-}, \mathrm{K}^{+}$, and $\mathrm{NH}_{4}{ }^{+}$-from 2 to 4 times, respectively, and those of $\mathrm{PM1-bound} \mathrm{SO}_{4}{ }^{2-}$ and $\mathrm{PO}_{4}{ }^{3-}$ less than 2. During runoff, the $\mathrm{PM}$ sample with water and easily soluble macro-components can affect the $\mathrm{pH}$ of leaching solution; $\mathrm{pH}$ in turn can affect the leaching behavior of As. It is obvious that As compounds may vary depending on their sensitivity to a $\mathrm{pH}$ solution changes; some can be released under neutral pH conditions; some has a tendency to dissolve into acid solution, e.g., arsenic in carbonate-bound, surface oxide-bound ions [24].

Significance of emission sources in shaping As(III) and As $(V)$ solubility can be seen especially in winter season, when emission from fuels combustion (mainly hard and brown coal) prevails in total emission. There has been found positive correlation between PM1 concentrations and As concentrations (Fig. 2), As total and As soluble concentrations (Fig. 3), As soluble and $\mathrm{As}(\mathrm{V})$ concentrations (Fig. 4) and negative between As(III) and As soluble (Fig. 5) in winter season. The correlations suggest that PM1-bound As comes from combustion emission (probably municipal emission - heating with use coal) and As compounds from combustion influence not only amounts of soluble $\mathrm{As}(\mathrm{V})$ in the ambient air but also its share in total PM1-bound As. As from combustion process is emitted mainly as arsenic trioxide, and prevailing oxidative As forms in PM are explained by oxidation of trivalent forms by oxidants such as ozone [27, 28]. Seasonal changes in PM2.5-bound As(III) and $\mathrm{As}(\mathrm{V})$ had been noticed in research conducted in Jinan city situated in Shandong Province of China (area under

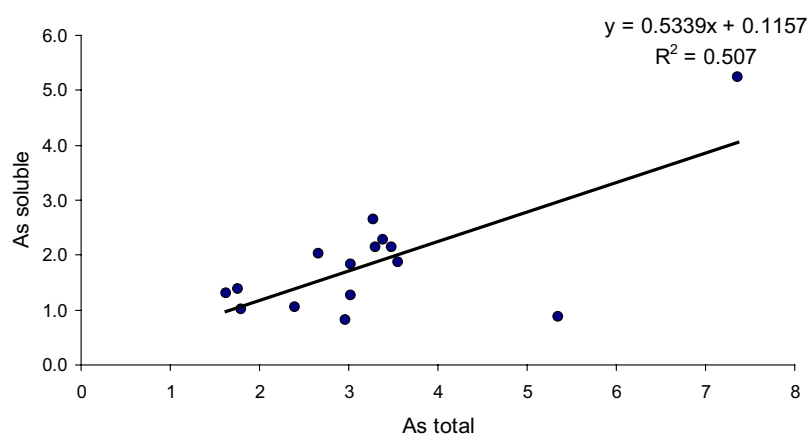

Fig. 3 As soluble versus As total in winter

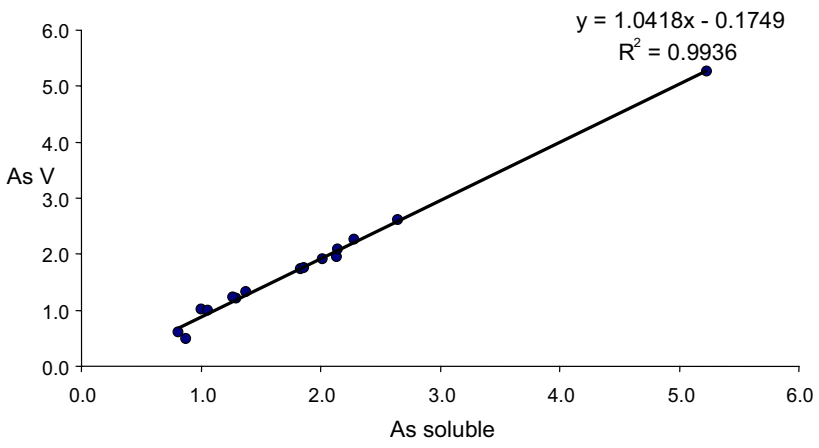

Fig. $4 \mathrm{As}(\mathrm{V})$ versus As soluble in winter

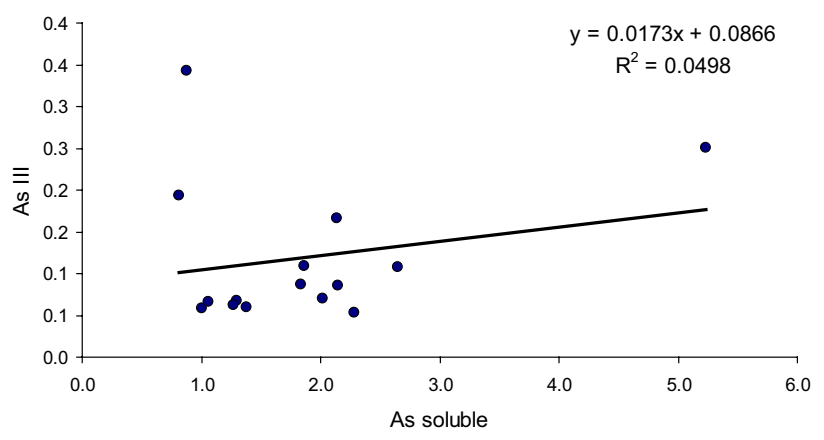

Fig. 5 As(III) versus As soluble in winter

the influence of coal combustion emissions, especially in winter). Analysis of As species in PM showed that only in some winter samples of PM2.5, As(III) was determined; the rest of As was present as $\mathrm{As}(\mathrm{V})$ [27].

In winter, water-soluble As(III) also may came from coal combustion (not oxidized arsenic trioxide) and from the other As sources like road traffic, industry and resuspended dust. In summer season, both As(III) and As(V) were positively correlated with As soluble (Figs. 6, 7), but As soluble was not correlated with As total (Fig. 8) and As total was not correlated with PM1(Fig. 9). The percentage 


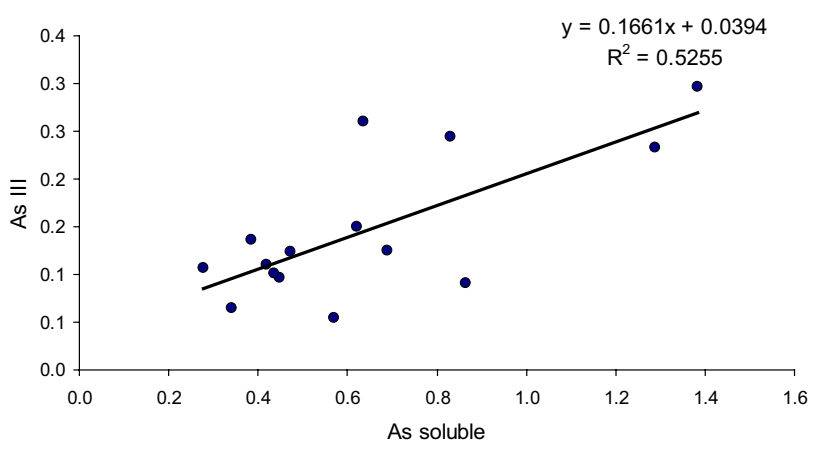

Fig. 6 As(III) versus As soluble in summer

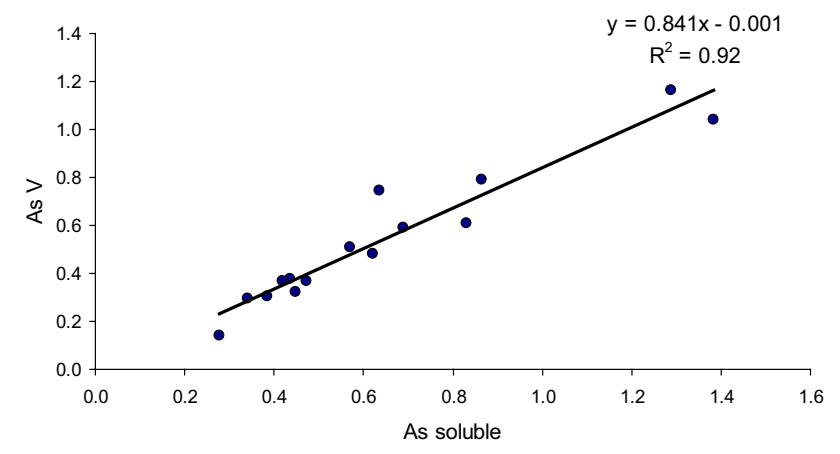

Fig. $7 \mathrm{As}(\mathrm{V})$ versus As soluble in summer

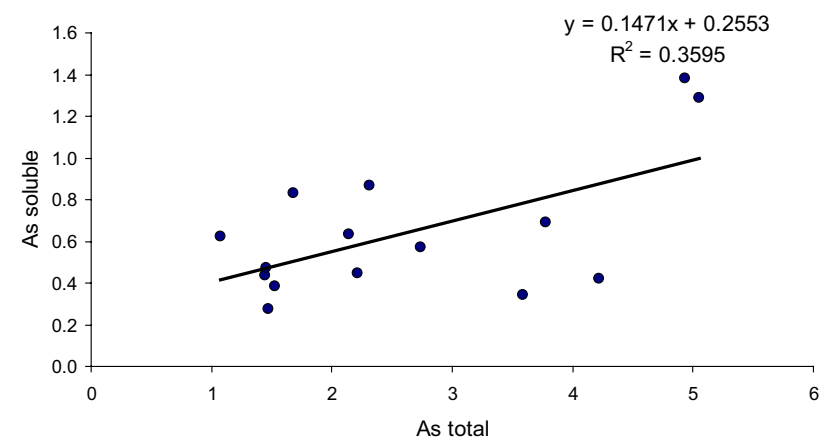

Fig. 8 As soluble versus As total in summer

amount of water-soluble fraction of $\mathrm{As}$ (III) in relation to total As amount were almost two times higher and $\mathrm{As}(\mathrm{V})$ was 2.5 times less compared to that in winter season.

The seasonal differences mentioned above probably can be a consequence of both prevailing emission from fuel combustion in winter and a various shares such as emissions from industry, traffic and re-suspended dust in the total emission in winter and summer.

In summer, water-soluble $\mathrm{As}(\mathrm{III})$ and $\mathrm{As}(\mathrm{V})$ in PM1 can also come from second emission from surfaces such as farmlands and dumplings. In winter, this kind of emission

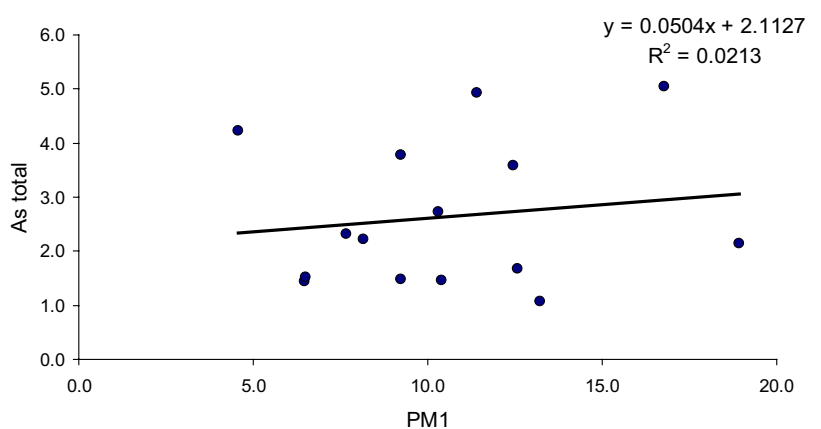

Fig. 9 As total versus PM1 in summer

is limited because of snow cover. It should be taken into account that PM1 may be transported from distant regions, being under influence of different sources of emission, than considered.

\section{Summary}

The research on speciation of inorganic water-soluble As in PM1, collected in industrial city Zabrze, showed that $\operatorname{As}(\mathrm{V})$ was dominating soluble species and the ambient concentration of soluble $\mathrm{As}(\mathrm{III})$ and $\mathrm{As}(\mathrm{V})$ as well as their mass percentage in water-soluble and total As changed seasonally.

In winter season, when emissions from solid fuels combustion (mainly coal) prevailed, ambient concentration of soluble $\mathrm{As}(\mathrm{V})$ was about three times higher than in summer and accounted for $55 \%$ of total As. Ambient mass of As(III) was about 3.7\% of the total As mass. We recorded several times higher concentrations of $\mathrm{OC}$ and some water-soluble ions, especially $\mathrm{Cl}^{-}$and $\mathrm{NO}^{3-}$, than in summer. During summer, when the sources of As may be more differentiated (industry, traffic, secondary), emission from some surfaces, e.g., soils, roads, farmlands and dumps, soluble As $(\mathrm{V})$, accounted for $23 \%$ of total As, while soluble As(III) $6.7 \%$.

Significant increase in the mean concentrations of PM1, PM1-bound As and PM1- bound soluble $A s(V)$ in winter may indicate that prevailing amount of soluble $A s(V)$ was coming from solid fuel (coal) combustion and originally appeared as trivalent until it has been oxidized in atmosphere. Additionally recorded several times higher concentrations of $\mathrm{OC}$ and some water-soluble ions (especially $\mathrm{Cl}^{-}$and $\mathrm{NO}^{3-}$ ) in winter can have impact on more effective water solution extraction of PM-bound As (V) than in summer.

Acknowledgements The research was financed in the frame of project "Studies on the speciation of chromium and arsenic in 
size-fractionated urban aerosol" (UMO-2016/23/N/ST10/03032) by National Science Center, Poland (NCN), and sample collecting was a part of the project (Grant) No. 2012/07/D/ST10/02895 (ID 202319) financed by the National Science Centre, Poland (NCN).

\section{Compliance with ethical standards}

Conflict of interest The authors declare that they have no conflict of interest.

Open Access This article is distributed under the terms of the Creative Commons Attribution 4.0 International License (http://creativeco mmons.org/licenses/by/4.0/), which permits unrestricted use, distribution, and reproduction in any medium, provided you give appropriate credit to the original author(s) and the source, provide a link to the Creative Commons license, and indicate if changes were made.

\section{References}

1. Matschullat J (2000) Arsenic in the geosphere-a review. Sci Total Environ 249:297-312

2. WHO, Air Quality Guidelines for Europe (2001) WHO regional publications, 2nd edn. Regional Office for Europe, Copenhagen

3. Birmili W, Allen AG, Bary F, Harrison RM (2016) Trace metal concentrations and water solubility in size-fractionated atmospheric particles and influence of road traffic environ. Sci Technol 40:144-1153

4. Chen B, Stein AF et al (2013) Size distribution and concentrations of heavy metals in atmospheric aerosols originating from industrial emissions as predicted by the HYSPLIT model. Atmos Environ 71:234-244

5. Rybak J (2015) Accumulation of major and trace elements in spider webs. Water Air Soil Pollut 226(4):105. https://doi. org/10.1007/s11270-015-2369-7

6. Rogula-Kozlowska W, Błaszczak B, Klejnowski K (2011) Concentrations of PM2.5, PM2.5-10 and PM - related elements at two heights in an urban background area in Zabrze (Poland). Arch Environ Prot 37:31-49

7. Rogula-Kozłowska W, Majewski G, Czechowski P (2015) The size distribution and origin of elements bound to ambient particles: a case study of a Polish urban area. Environ Monit Assess 187:240

8. Rogula-Kozłowska W (2016) Size-segregated urban particulate matter: mass closure, chemical composition, and primary and secondary matter content. Air Qual Atmos Health 9:533-550

9. Tiwari S, Chate DM, Pragya P, Ali K, Bisht DS (2012) Variations in Mass of the PM10, PM2.5 and PM1 during the Monsoon and the Winter at New Delhi Aerosol. Air Qual Res 12:20-29

10. WHO. Health Risks of Particulate Matter from Long-range Transboundary Air Pollution (2006) Copenhagen, World Health Organization Regional Office for Europe. www.euro.who.int/_ data/assets/pdf_file/0006/78657/E88189.pdf

11. Labiris NR, Dolovich MB (2003) Pulmonary drug delivery. Part I: physiological factors affecting therapeutic effectiveness of aerosolized medications. J Clin Pharmacol 56:588-599
12. Lewis A (2012) Speciated arsenic in air: measurement methodology and risk assessment considerations. J Air Waste Manag Assoc 62:2-17

13. Fodor $P$ (2001) Arsenic speciation in environment. In: Ebdon $L$ et al (eds) Trace element speciation for environment, food and health. Royal Society of Chemistry, Cambridge, pp 201-211

14. Widziewicz K, Rogula-Kozłowska W, Loska K (2016) Cancer risk from arsenic and chromium species bound to PM2.5 and PM1—a Polish case study. Atmos Pollut Res 7:884-894

15. Tirez $\mathrm{K}$ et al (2015) Speciation of inorganic arsenic in particulate matter by combining HPLC/ICP MS and XANES analyses. J Anal At Spectrom 30:2074

16. Huang $M$ et al (2014) Arsenic speciation in total contents and bioaccessible fractions in atmospheric particles related to human intakes. Environ Pollut 188:37-44

17. Sánchez A et al (2008) Arsenic speciation study of PM2.5 in an urban area near a copper smelter. Atmos Environ 42:6487-6495

18. Rogula-Kozłowska W et al (2014) Spatial and seasonal variability of the mass concentration and chemical composition of $\mathrm{PM}_{2.5}$ in Poland. Air Qual Atmos Health 7:41-58

19. Rogula-Kozłowska W, Klejnowski K (2013) Submicrometer aerosol in Rural and Urban backgrounds in Southern Poland: primary and secondary components of PM1. Bull Environ Contam Toxicol 90:103-109

20. Rogula-Kozłowska W et al (2019) Seasonal variations of $\mathrm{PM}_{1}$-bound water concentration in urban areas in Poland. Atmos Pollut Res 10(1):267-273

21. Widziewicz K et al (2017) PM1 and PM1-bound metals during dry and wet periods: ambient concentration and health effects. Environ Eng Sci 34:312-320

22. Namieśnik J, Konieczka P, Zygmunt B (2010) Ocena i Kontrola Jakości Wyników Pomiarów Analitycznych. WNT, Warszawa

23. Sysalova J (2011) Methodological study of extraction procedures applied to urban particulate matter. Cent Eur J Chem 9:1071-1079

24. Hao Y (2010) pH effect on the arsenic separation in waste water of coal based power plant master's thesis University of Tennessee, Google Scholar

25. Yadav S, Satsangi PG (2013) Characterization of particulate matter and its related metal toxicity in an urban location in South West India. Environ Monit Assess 185:7365-7379

26. Klejnowski K, Pastuszka J, Rogula-Kozłowska W et al (2012) Layer of summer and winter airborne particles in Zabrze, Poland. Bull Environ Contam Toxicol 88:255-259

27. Yin $X$, Wang $L$ et al (2017) Arsenic accumulation and speciation of PM2.5 and relevant health risk assessment in Jinan, China. Pol J Environ Stud 26:949-954

28. Šlejkovec Z, Salma I et al (2000) Speciation of arsenic in coarse and fine urban aerosols using sequential extraction combined with liquid chromatography and atomic fluorescence detection. Fresenius J Anal Chem 366:830-834

Publisher's Note Springer Nature remains neutral with regard to jurisdictional claims in published maps and institutional affiliations. 